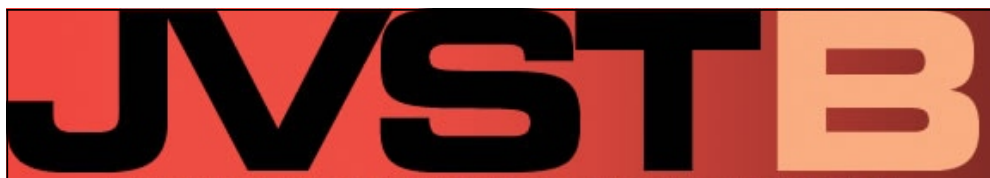

JOURNAL OF VACUUM SCIENCE AND TECHNOLOGY B

\title{
Process considerations for layer-by-layer 3D patterning of silicon, using ion implantation, silicon deposition, and selective silicon etching
}

Kristinn B. Gylfason, Andreas C. Fischer, B. Gunnar Malm, Henry H. Radamson, Lyubov M. Belova et al.

Citation: J. Vac. Sci. Technol. B 30, 06FF05 (2012); doi: 10.1116/1.4756947

View online: http://dx.doi.org/10.1116/1.4756947

View Table of Contents: http://avspublications.org/resource/1/JVTBD9/v30/i6

Published by the AVS: Science \& Technology of Materials, Interfaces, and Processing

\section{Related Articles}

Study of defect mechanisms in partly filled stamp cavities for thermal nanoimprint control

J. Vac. Sci. Technol. B 30, 06FB03 (2012)

Nanofabrication of high aspect ratio (50:1) sub-10nm silicon nanowires using inductively coupled plasma etching J. Vac. Sci. Technol. B 30, 06FF02 (2012)

Formation of high quality nano-crystallized Ge films on quartz substrates at moderate temperature J. Vac. Sci. Technol. B 30, 051201 (2012)

Maskless fabrication of selectively sized silicon nanostructures for solar cell application

J. Vac. Sci. Technol. B 30, 041401 (2012)

Effects of showerhead hole structure on the deposition of hydrogenated microcrystalline silicon thin films by vhf PECVD

J. Vac. Sci. Technol. A 30, 04D113 (2012)

\section{Additional information on J. Vac. Sci. Technol. B}

Journal Homepage: http://avspublications.org/jvstb

Journal Information: http://avspublications.org/jvstb/about/about_the_journal

Top downloads: http://avspublications.org/jvstb/top_20_most_downloaded

Information for Authors: http://avspublications.org/jvstb/authors/information_for_contributors

\section{ADVERTISEMENT}

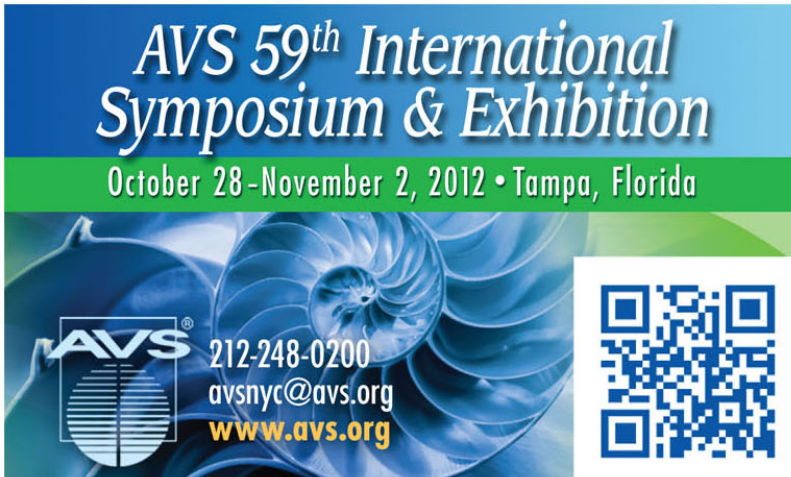

DIVISION/GROUP PROGRAMS:

- Advanced Surface Engineering

- Applied Surface Science

Biomaterial Interfaces

- Electronic Materials \& Processing

- Magnetic Interfaces \& Nanostructures

- Manufacturing Science \& Technology

- MEMS \& NEMS

- Nanometer-Scale Science \& Technology

- Plasma Science \& Technology

- Surface Science

- Thin Film

- Vacuum Technology
FOCUS TOPICS:

- Actinides \& Rare Earths

- Biofilms \& Biofouling: Marine, Medical, Energy

- Biointerphases

- Electron Transport at the Nanoscale

- Energy Frontiers

- Exhibitor Technology Spotligh

- Graphene \& Related Materials

- Helium Ion Microscopy

- InSitu Microscopy \& Spectroscopy

- Nanomanufacturing

- Oxide Heterostructures-Interface Form \& Function

- Scanning Probe Microscopy

- Spectroscopic Ellipsometry

- Transparent Conductors \& Printable Electronics

- Tribology 


\title{
Process considerations for layer-by-layer 3D patterning of silicon, using ion implantation, silicon deposition, and selective silicon etching
}

\author{
Kristinn B. Gylfason and Andreas C. Fischer \\ Microsystem Technology Lab (MST), KTH Royal Institute of Technology, Osquldasväg 10, \\ SE-10044 Stockholm, Sweden \\ B. Gunnar Malm and Henry H. Radamson \\ Integrated Devices and Circuits Lab (IDC), KTH Royal Institute of Technology, Isafjordsgatan 22, \\ SE-16440 Kista, Sweden \\ Lyubov M. Belova \\ Engineering Materials Physics Lab (EMP), KTH Royal Institute of Technology, Brinellvägen 23, \\ SE-10044 Stockholm, Sweden \\ Frank Niklaus ${ }^{\text {a) }}$ \\ Microsystem Technology Lab (MST), KTH Royal Institute of Technology, Osquldasväg 10, \\ SE-10044 Stockholm, Sweden
}

(Received 3 July 2012; accepted 17 September 2012; published 9 October 2012)

\begin{abstract}
The authors study suitable process parameters, and the resulting pattern formation, in additive layer-by-layer fabrication of arbitrarily shaped three-dimensional (3D) silicon (Si) micro- and nanostructures. The layer-by-layer fabrication process investigated is based on alternating steps of chemical vapor deposition of $\mathrm{Si}$ and local implantation of gallium ions by focused ion beam writing. In a final step, the defined 3D structures are formed by etching the $\mathrm{Si}$ in potassium hydroxide, where the ion implantation provides the etching selectivity. (C) 2012 American Vacuum Society. [http://dx.doi.org/10.1116/1.4756947]
\end{abstract}

\section{INTRODUCTION}

In additive layer-by-layer manufacturing techniques, several patterned layers of a material are stacked on top of each other. ${ }^{1-16}$ These techniques provide an effective way of manufacturing arbitrarily shaped three-dimensional (3D) structures. Different additive layer-by-layer manufacturing approaches exist, which make use of various materials such as polymers, waxes, ceramics, semiconductors, and metals. The techniques include stereolithography, ${ }^{1,2}$ solid ground curing, ${ }^{1}$ selective laser sintering, ${ }^{1,6}$ 3D inkjet printing, ${ }^{1}$ laminated object modeling, ${ }^{2,7}$ and fused deposition modeling, ${ }^{1,8-16}$ including beam-assisted deposition techniques. ${ }^{10-15}$ The achievable dimensions of the 3D structures strongly depend on the used technology and can range from several tens of nm to tens of $\mu \mathrm{m}$.

Recently, we proposed and demonstrated a simple process for additive layer-by-layer fabrication of 3D silicon ( $\mathrm{Si}$ ) nanostructures. ${ }^{17}$ The process consists of cycles of chemical vapor deposition of an Si layer and local ion implantation into the layer by focused ion beam (FIB) writing, and is finished off with a final etch to form the 3D $\mathrm{Si}$ structures defined by the implantation. This process makes use of the high etch selectivity that can be achieved in semiconductor materials by local ion implantation, ${ }^{18-28}$ thereby forming patterns in the material with lateral dimensions of down to $20 \mathrm{~nm} .^{25}$ The proposed implementation of the layer-by-layer fabrication process is schematically illustrated in Fig. 1. First, a pattern is defined with implanted gallium ions $\left(\mathrm{Ga}^{+}\right)$ in an Si substrate using FIB writing (Fig. 1, step 1). This is

a)Electronic mail: frank.niklaus@ee.kth.se followed by chemical vapor deposition of a thin Si layer (Fig. 1, step 2), and another pattern definition by $\mathrm{Ga}^{+}$implantation into the new layer (Fig. 1, step 3). By repeating steps 2 and 3 over and over, the 3D structure is defined within the deposited Si layers. The local implantation of $\mathrm{Ga}^{+}$ions into $\mathrm{Si}$ results in an etch selectivity of the $\mathrm{Si}$ in potassium hydroxide $(\mathrm{KOH})$ wet etching. Thus, the defined 3D $\mathrm{Si}$ structures can be formed by selective free-etching in $\mathrm{KOH}$, as a final patterning step (Fig. 1, step 4). ${ }^{17}$

Well known methods such as selective epitaxy of silicon or silicon germanium rely on lithographic patterning and subsequent etching of an oxide or nitride hardmask in the areas of desired growth. While single layer structures of high quality are obtained, the continuation to an arbitrary second layer is impossible, since the hardmask areas cannot serve as starting point for silicon growth. In particular, suspended structures, which are of prime importance in micromechanical applications, cannot be achieved.

In the present work, we study in more detail the growth of Si on the four different surfaces encountered in the 3D patterning process (bulk or deposited Si, implanted or not implanted), and how the grow mode affects the achievable resolution. Furthermore, we simulate $\mathrm{Ga}^{+}$implantation depths at different implantation energies and derive suitable process parameters for the formation and definition of patterned 3D Si structures.

\section{EXPERIMENT}

To investigate the pattern formation and definition of multilayer 3D patterns in $\mathrm{Si}$, we created three-layer Si structures by three implantations and two depositions. The test patterns contained all possible overlaps of the layers. We evaluated two different thicknesses of the deposited Si layer, 


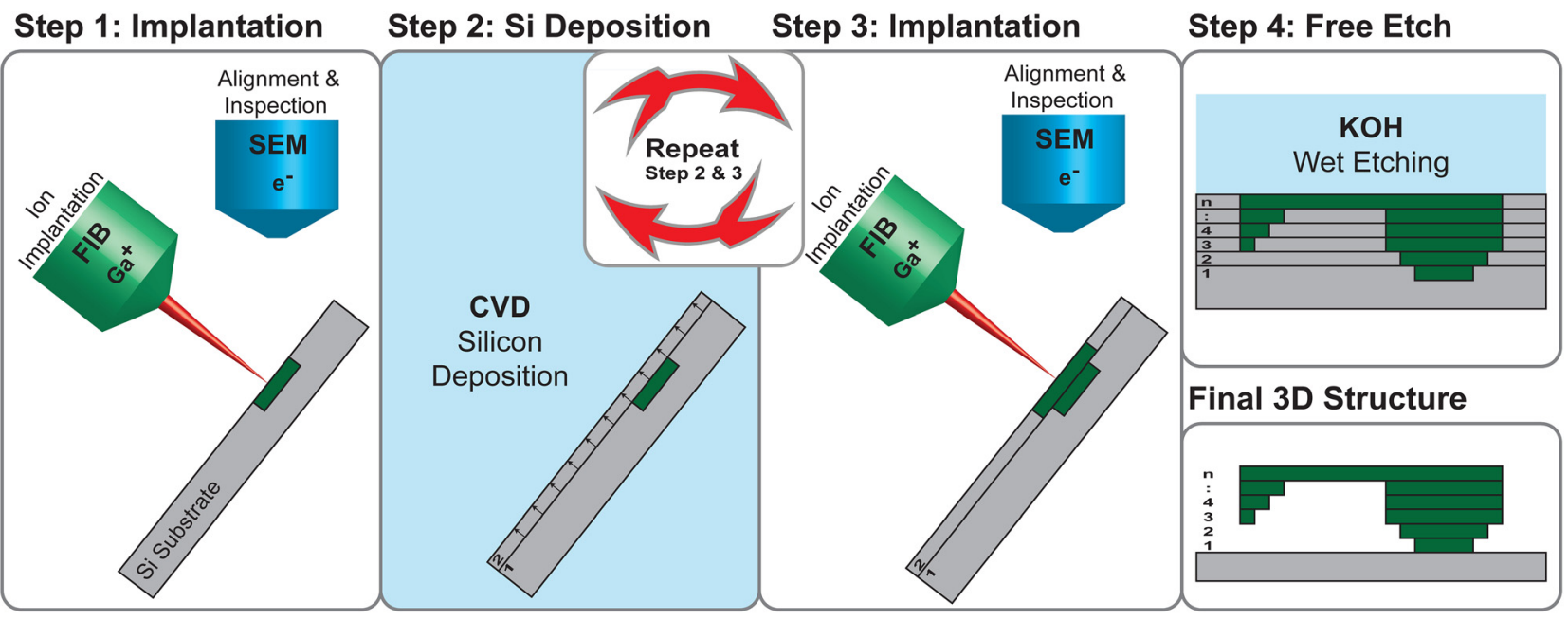

FIG. 1. (Color online) Additive layer-by-layer fabrication of Si structures. Step 1: Local implantation of $\mathrm{Ga}^{+}$ions into the surface of an Si substrate by FIB writing. Step 2: Chemical vapor deposition (CVD) of an Si layer. Step 3: Local implantation of $\mathrm{Ga}^{+}$ions in the deposited Si layer using FIB writing. Subsequently, Steps 2 and 3 are repeated until the 3D structures are defined in the Si layers by the locally implanted $\mathrm{Ga}^{+}$. Step 4: Selective etching of the nonimplanted Si in KOH to obtain the final 3D Si structures. Adapted from Ref. 17.

40 and $120 \mathrm{~nm}$, while keeping the ion acceleration voltage fixed at $30 \mathrm{kV}$ in all implantations. For the experiments, we used (100) silicon wafers [p-type, 14-22 $\Omega \mathrm{cm}$ (Wafer A) and p-type, 10-20 $\Omega \mathrm{cm}$ (Wafer B)] and implanted an area dose of $10 \mathrm{pC} / \mu^{2}$ of $\mathrm{Ga}^{+}$ions, using a Nova 600 NanoLab focused ion beam tool from FEI (the Netherlands). To guide our choice of layer thicknesses, we simulated the implantation of $\mathrm{Ga}^{+}$ions into $\mathrm{Si}$ using the TRIM code. ${ }^{29}$

Before each Si layer deposition, we cleaned the silicon wafers by the following steps: $10 \mathrm{~s}$ dip in $5 \%$ hydrofluoric acid (HF), 5 min wash in deionized (DI) water, 5 min oxidation in hot $\mathrm{H}_{2} \mathrm{SO}_{4}: \mathrm{H}_{2} \mathrm{O}_{2} 3: 1,5$ min DI wash, $10 \mathrm{~s}$ dip in $5 \%$ $\mathrm{HF}$, and $5 \mathrm{~min}$ DI wash. We grew the Si layers from a disilane $\left(\mathrm{Si}_{2} \mathrm{H}_{6}\right)$ precursor, at a pressure of $2.6 \mathrm{kPa}$ and a temperature of $635^{\circ} \mathrm{C}$, using an Epsilon 2000 single wafer epitaxy tool from ASM International N.V. (the Netherlands). We patterned two different wafers. On both wafers, we did an identical layer 1 implant directly into the substrate, while the thickness of the deposited layers differed: Wafer A had a layer 2 target thickness of $120 \mathrm{~nm}$ ( $936 \mathrm{~s}$ deposition) and a layer 3 target thickness of $40 \mathrm{~nm}$ ( $312 \mathrm{~s}$ deposition). Wafer B had at target thickness of $40 \mathrm{~nm}$ for both deposited layers. During the wafer loading procedure, the wafers were exposed to the temperature steps of $850^{\circ} \mathrm{C}$ for $13 \mathrm{~s}$, followed by $725^{\circ} \mathrm{C}$ for $120 \mathrm{~s}$.

After the final implantation, we treated the wafers with a rapid thermal anneal in an argon atmosphere at $650{ }^{\circ} \mathrm{C}$ for 30 s. Finally, we formed the structures by an etch in $\mathrm{KOH}$. First, we dipped the wafers for $3 \mathrm{~s}$ in 5\% HF, to remove the native $\mathrm{SiO}_{2}$, next we etched them in $30 \% \mathrm{KOH}$ at $36^{\circ} \mathrm{C}$ for $5 \mathrm{~min} 30 \mathrm{~s}$, and finally washed them in DI water for $3 \mathrm{~min}$ and dried with $\mathrm{N}_{2}$.

In an attempt to reduce the lattice damage of the Si surface due to the $\mathrm{Ga}^{+}$ion implantation, an additional experiment was performed in which an $\mathrm{Si}$ wafer with $\mathrm{Ga}^{+}$ion implanted patterns was in situ cleaned and annealed in the epi reactor at $1050^{\circ} \mathrm{C}$ for $2 \mathrm{~min}$ prior to the $\mathrm{Si}$ deposition step.

\section{RESULTS AND DISCUSSION}

Figure 2 shows a scanning electron micrograph (SEM) of a three-layer test structure on Wafer A. The structure contains areas of overlapping implantations in layers: 1-2, 2-3, and 1-2-3, as well as areas where layers 2 and 3 overlap with the substrate. The structures in all layers are resolved, although some differences between layers can be observed.

The differences in the appearance of the layers are a consequence of the implantation method used. To maintain layer homogeneity, epitaxial growth of mono-crystalline $\mathrm{Si}$ would be preferred for a layer-by-layer manufacturing process. In addition, mono-crystalline $\mathrm{Si}$ has superior mechanical and
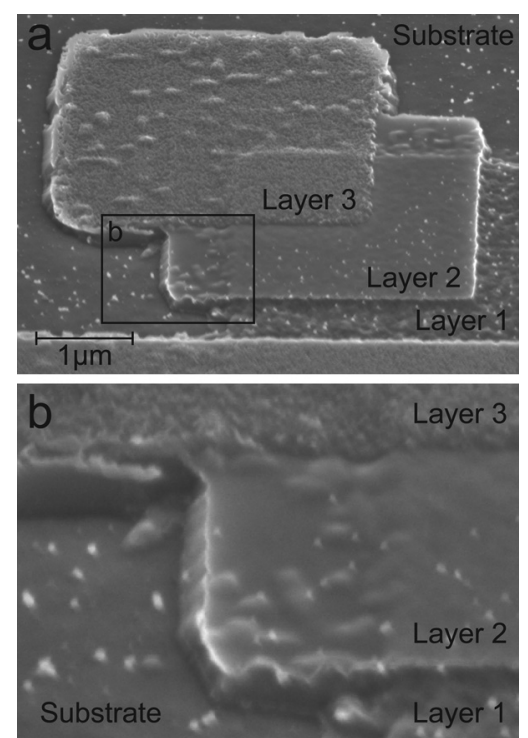

FIG. 2. Three-layer test structure made by three implantations and two depositions. The structure shows all possible overlaps of the three layers, as well as overlaps of layers 2 and 3 with the substrate. (a) Overview of the whole structure. (b) Enlarged view of the overlap of layer 2 with the nonimplanted $\mathrm{Si}$ on the left, and with the layer 1 implantation on the right. 
electrical properties that are attractive for electromechanical components. However, implantation of $\mathrm{Ga}^{+}$ions into $\mathrm{Si}$ breaks down the crystalline structure and leaves the implanted surface layer amorphous. ${ }^{30}$ Subsequent Si growth will thus be polycrystalline on implanted layers, while epitaxy is still possible outside implanted areas. As a result, the thickness of the layer grown on the implanted areas can be up to double the thickness of the layer grown on nonimplanted areas. ${ }^{17}$ This effect is known from so called differential epitaxy, where the growth rates over different types of exposed surfaces vary significantly under identical conditions (gas flow, partial pressure, and temperature). ${ }^{31,32}$ This can clearly be seen in the enlarged region shown in Fig. 2(b), where layer 2 grows on nonimplanted silicon on the left side, and on the layer 1 implantation on the right side. On the left side the layer 2 surface is smooth (apart from a few local defects), and the left sidewall has a slope characteristic of an Si (111) plane, indicating that layer 2 grows epitaxially in this region. In contrast, the right sidewall of layer 2 is jagged, as is more characteristic of a polycrystalline layer. Furthermore, the region of the layer grown on the implanted layer 1 (right side) is thicker than the region grown on the nonimplanted layer 1 (left side). In an attempt to reduce the lattice damage of the Si surface due to the $\mathrm{Ga}^{+}$ion implantation, and to allow subsequent epitaxial growth of a mono-crystalline $\mathrm{Si}$ layer, an $\mathrm{Si}$ wafer with $\mathrm{Ga}^{+}$ ion implanted patterns was in situ cleaned and annealed in the epi reactor at $1050^{\circ} \mathrm{C}$ for $2 \mathrm{~min}$ prior to the $\mathrm{Si}$ deposition step. However in this experiment, it was observed that none of the implanted structures were resolved in the $\mathrm{KOH}$ etch, presumably due to the out-diffusion of the $\mathrm{Ga}^{+}$ions during the high-temperature annealing step.

For successful layer-by-layer patterning, the thickness of the deposited layers must match the implantation depth of the $\mathrm{Ga}^{+}$ions. If the deposited layer is too thin, the $\mathrm{Ga}^{+}$ions will penetrate through the layer and implant the layer below. Figure 3 shows a TRIM simulation of the implantation of an area dose of $10 \mathrm{pC} / \mu \mathrm{m}^{2}\left(6 \times 10^{15} \mathrm{~cm}^{-2}\right)$ of $\mathrm{Ga}^{+}$ions into $\mathrm{Si}$, at ion energies in the range from 10 to $50 \mathrm{keV}$. The thickness of the layer that reaches a $\mathrm{Ga}^{+}$dopant concentration above $2.2 \times 10^{19} \mathrm{~cm}^{-3}$, the threshold required for etch selectivity in $\mathrm{KOH},{ }^{26}$ ranges from $29 \mathrm{~nm}$ at $10 \mathrm{keV}$ to $85 \mathrm{~nm}$ at $50 \mathrm{keV}$. At $30 \mathrm{keV}$, the resulting Si layer thickness in which the critical

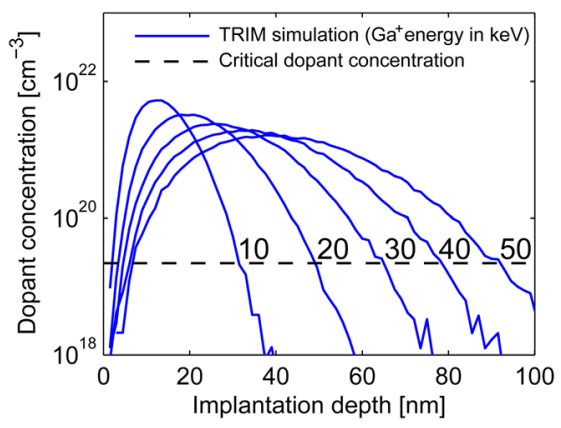

FIG. 3. (Color online) Simulation of the implantation of an area dose of 10 $\mathrm{pC} / \mu \mathrm{m}^{2}\left(6 \times 10^{15} \mathrm{~cm}^{-2}\right)$ of $\mathrm{Ga}^{+}$ions into $\mathrm{Si}$, at ion energies in the range from 10 to $50 \mathrm{keV}$.

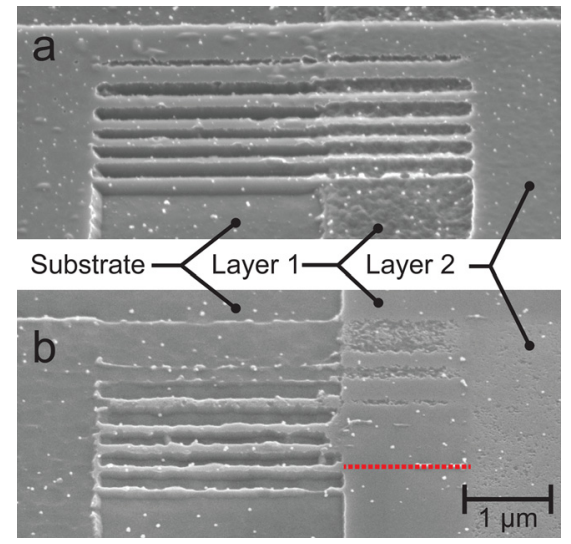

FIG. 4. (Color online) (a) Lines patterned in the $120 \mathrm{~nm}$ thick layer 2 of Wafer A. (b) Same pattern in the $40 \mathrm{~nm}$ thick layer 2 of Wafer B.

implantation dose is exceeded is about $60 \mathrm{~nm}$, as depicted in Fig. 3. Furthermore, the simulation suggests that the critical implantation dose is not reached in a few nm thick layer near the Si surface.

In Fig. 4, we compare the $120 \mathrm{~nm}$ thick deposited Si layer 2 of Wafer A [Fig. 4(a)] with the $40 \mathrm{~nm}$ thick deposited $\mathrm{Si}$ layer 2 of Wafer B [Fig. 4(b)]. The patterned structures consist of a line pattern, with line widths down to $33 \mathrm{~nm}$. The ion implanted pattern in the $120 \mathrm{~nm}$ thick layer is resolved, both in the areas overlapping the substrate and in the areas overlapping the implanted layer 1 [Fig. 4(a)]. In the $40 \mathrm{~nm}$ thick layer 2 on Wafer B, however, the lines are only visible in the regions overlapping the substrate, while in the regions overlapping layer 1 they are completely vanished. A possible explanation is that the targeted thickness of $40 \mathrm{~nm}$ for the deposited Si layer was not obtained on Wafer B, due to slow initial Si growth on the surface. In an effort to reduce overall process temperature, and thus reduce diffusion of the implanted $\mathrm{Ga}^{+}$, the customary in situ $\mathrm{H}_{2}$ clean at $950{ }^{\circ} \mathrm{C}$ or above was omitted. Thus, some residues of native surface oxide may have slowed down initial nucleation in the silicon epitaxial process. A low temperature alternative, to prepare the surface for initial nucleation, would be in situ sputtering removal of the native oxide using, e.g., Ar ions, which is a standard approach in semiconductor processing.

A slow initial growth of the $\mathrm{Si}$ would not be visible in the same way in the thicker $120 \mathrm{~nm}$ thick Si layer on Wafer A. The thickness of the grown Si layer does not have the same impact on the resolved pattern on areas in which the underlying layer is not ion implanted, as shown in Fig. 4(b) where the implanted pattern is resolved in the area where the substrate layer has no implanted $\mathrm{Ga}^{+}$ions.

\section{SUMMARY AND CONCLUSIONS}

We have investigated the pattern definition in additive layer-by-layer fabrication of 3D Si structures by forming $\mathrm{Si}$ structures in three layers. We found that the $\mathrm{Si}$ growth process is affected in areas where a pattern is defined by the $\mathrm{Ga}^{+}$ion implantation, as compared to areas without implanted $\mathrm{Ga}^{+}$ions. In general, the epitaxial growth of mono-crystalline Si would be preferred for the proposed 
layer-by-layer manufacturing process, due to the potentially increased homogeneity of the layers, and the superior mechanical and electrical properties of mono-crystalline $\mathrm{Si}$ for electromechanical devices, as compared to amorphous or polycrystalline Si. However, the damage induced in the Si lattice by the implantation of the $\mathrm{Ga}^{+}$ions makes it difficult to grow epitaxial mono-crystalline Si layers on top of $\mathrm{Ga}^{+}$ion implanted areas. Therefore, either suitable process steps for the removal of the lattice damage in the Si have to be implemented, or, alternatively, it may be possible to use ion implantation of smaller $\mathrm{H}^{+}$or $\mathrm{He}^{+}$ions for the pattern definition. This could potentially cause less damage to the Si lattice structure while still providing $\mathrm{Si}$ etch selectivity in available etches. ${ }^{27,28}$ The aim of this research is to work toward a layer-by-layer manufacturing technology for 3D $\mathrm{Si}$ nanostructures that can be implemented as a switched process in a single automated tool. This would enable printing of 3D Si nanostructures directly from 3D computer aided design (CAD) models of the structures, without the need for full clean-room facilities, and could provide custom silicon nanostructures for low-volume high-margin application fields, such as telecommunications (e.g., 3D Si photonic crystals) and medicine (e.g., neural implants).

\section{ACKNOWLEDGMENT}

The authors are grateful for funding from the European Commission through the FP7-ERC-M\&M's starting grant (No. 277879).

${ }^{1}$ B. Wendel, D. Rietzel, F. Kühnlein, R. Feulner, G. Hülder, and E. Schmachtenberg, Macromol. Mater. Eng. 293, 799 (2008).

${ }^{2}$ J. Stampfl, S. Baudis, C. Heller, R. Liska, A. Neumeister, R. Kling, A. Ostendorf, and M. Spitzbart, J. Micromech. Microeng. 18, 125014 (2008).

${ }^{3}$ G. von Freymann, A. Ledermann, M. Thiel, I. Staude, S. Essig, K. Busch, and M. Wegener, Adv. Funct. Mater. 20, 1038 (2010).

${ }^{4}$ M. Deubel, G. von Freymann, M. Wegener, S. Pereira, K. Busch, and C. M. Soukoulis, Nature Mater. 3, 444 (2004).

${ }^{5}$ K. Busch, G. von Freymann, S. Linden, S. F. Mingaleev, L. Tkeshelashvili, and M. Wegener, Phys. Rep. 444, 101 (2007).
${ }^{6}$ J. P. Kruth, X. Wang, T. Laoui, and L. Froyen, Assem. Autom. 23, 357 (2003).

${ }^{7}$ A. Carlson et al., Appl. Phys. Lett. 98, 264104 (2011).

${ }^{8}$ J. A. Lewis, Adv. Funct. Mater. 16, 2193 (2006).

${ }^{9}$ D. B. Chrisey, Science 289, 879 (2000).

${ }^{10}$ G. M. Gratson, M. Xu, and J. A. Lewis, Nature 428, 386 (2004).

${ }^{11}$ S. Johansson, J. Å. Schweitz, H. Westberg, and M. Boman, J. Appl. Phys. 72, 5956 (1992).

${ }^{12}$ H. Westberg, M. Boman, S. Johansson, and J. Å. Schweitz, J. Appl. Phys. 73, 7864 (1993).

${ }^{13}$ P. B. Kargl, N. Arnold, and D. Bäuerle, Appl. Surf. Sci. 108, 257 (1997).

${ }^{14}$ I. Utke, P. Hoffmann, and J. Melngailis, J. Vac. Sci. Technol. B 26, 1197 (2008).

${ }^{15}$ A. A. Tseng, Small 1, 924 (2005).

${ }^{16}$ S. Reyntjens and R. Puers, J. Micromech. Microeng. 11, 287 (2001).

${ }^{17}$ A. C. Fischer, L. M. Belova, Y. G. M. Rikers, B. G. Malm, H. H. Radamson, M. Kolahdouz, K. B. Gylfason, G. Stemme, and F. Niklaus, Adv. Funct. Mater. 22, 4004 (2012).

${ }^{18}$ B. Schmidt, L. Bischoff, and J. Teichert, Sens. Actuators, A 61, 369 (1997).

${ }^{19}$ J. Brugger, G. Beljakovic, M. Despont, N. F. de Rooij, and P. Vettiger, Microelectron. Eng. 35, 401 (1997).

${ }^{20}$ N. Kawasegi, N. Morita, S. Yamada, N. Takano, T. Oyama, K. Ashida, J. Taniguchi, and I. Miyamoto, JSME Int. J., Ser. C 49, 583 (2006).

${ }^{21}$ H. X. Qian, W. Zhou, J. Miao, L. E. N. Lim, and X. R. Zeng, J. Micromech. Microeng. 18, 035003 (2008).

${ }^{22}$ P. Sievilä, N. Chekurov, and I. Tittonen, Nanotechnology 21, 145301 (2010).

${ }^{23}$ N. Chekurov, K. Grigoras, A. Peltonen, S. Franssila, and I. Tittonen, Nanotechnology 20, 065307 (2009).

${ }^{24}$ N. Chekurov, K. Grigoras, L. Sainiemi, A. Peltonen, I. Tittonen, and S. Franssila, J. Micromech. Microeng. 20, 085009 (2010).

${ }^{25}$ R. Böttger, L. Bischoff, B. Schmidt, and M. Krause, J. Micromech. Microeng. 21, 095025 (2011).

${ }^{26}$ L. Bischoff, B. Schmidt, H. Lange, and D. Donzev, Nucl. Instrum. Methods Phys. Res. B 267, 1372 (2009).

${ }^{27}$ E. J. Teo, M. B. H. Breese, E. P. Tavernier, A. A. Bettiol, F. Watt, M. H. Liu, and D. J. Blackwood, Appl. Phys. Lett. 84, 3202 (2004).

${ }^{28}$ E. J. Teo, E. P. Tavernier, M. B. H. Breese, A. A. Bettiol, F. Watt, M. H. Liu, and D. J. Blackwood, Nucl. Instrum. Methods Phys. Res. B 222, 513 (2004).

${ }^{29}$ J. F. Ziegler, J. P. Biersack, and M. D. Ziegler, SRIM-The Stopping and Range of Ions in Matter (SRIM, Chester, MD, 2008).

${ }^{30}$ M. Rommel, G. Spoldi, V. Yanev, S. Beuer, B. Amon, J. Jambreck, S. Petersen, A. J. Bauer, and L. Frey, J. Vac. Sci. Technol. B 28, 595 (2010).

${ }^{31}$ J. Pejnefors, S.-L. Zhang, H. H. Radamson, J. V. Grahn, and M. Ostling, J. Appl. Phys. 88, 1655 (2000).

${ }^{32}$ P. Ashburn, Mater. Sci. Semicond. Process. 4, 521 (2001). 